Thursfield: discusses errors and difficnlties of diagnosis, including obscure cases of fever and of odema, abdominal tumours and meningitis; and Mr. Seymour Barling deals with abdominal emergencies in childhood, especially with appendicitis and intussusception.

The IIedieal Chronicle - Professor W. Stirling, writing in the December issue of this journal, makes a plea for the study of the history of medicine, and gives a brief summary of the chief events in this field, founded on the recently published work of Professor Neuburger, now translated into 速nglish. Dr. R. T. Williamson writes on the use of the spectroscope in medicine, and Mr. Robert Ollerenshaw discusses the causes and treatment of coxa vara.

The Edinburgh Medical Junrnal - The late Professor Sir John \$truthers made provision in his will for a lecture on anatomy to be delivered every third year in the Royal College of Surgeons of Edinburgb. The first of these lectures, delivered by Dr. Arthur Keith, is published in the current number of this journal. It deals with the progress of anatomy during Struthers's life and with the various men of note by whom advances were made. Dr. William Russell writes on the position of the stomach as a guide to pyloric or duodenal dificulty; and Dr. James Ritchie contributes a cautions paper on the subject of vaccine therapy, noting that practice in this field is in advance of actual knowledge. Mr. J. W. Struthers records a case of a Dermoid Cyst of the Neck, containing a number of curious soft white concretions.

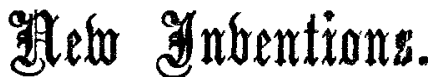

\section{A CONVENIENT AND SIMPLE APPARATUS FOR THECAL (LUMBAR) PUNCTURE.}

$I$ FNN that the little apparatus, of which an illustration is here given, facilitates lumbar puncture and enables the - operator to have greater control than if a syringe is used. Most authorities agree that suction should not be employed, therefore the syringe usually only serves as a handle. The syringe needle is usually unprovided with a stilette and the fuid is liable to become contaminated when dripping from the end of the needle after the syringe has been removed. A glass syringe is also liable to crack whilst being sterilised, and the process of sterilisation must take some time, as the ayringe must be put into cold water which is brought up to

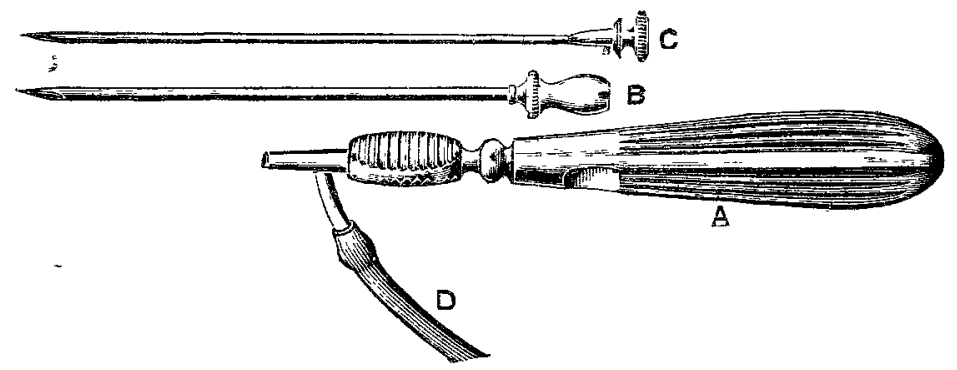

the boil and then of course must be allowed to cool down again before the syringe can be removed, if we wish to avoid the risk of cracking. This procedure takes at least a quarter of an hour. My little apparatus can be plunged straight into boiling water and taken out without any fear of injury. The cerebro-spinal flaid is conducted through the rubber trebe into a sterile test-tube, and thus there is practically no fear of contamination. If, after the puncture has been made, the fluid does not flow into the test-tube the holder $A$ is removed and uhe stilette $C$ passed down the needle $B$ I find, however, that it is only very occasionally that the stilette has to be used.

The apparatus was made for me by the Holborn Surgical Instrument Co., Limited, Holborn Circus, London, E.C. H. WANSEY BAYLY, M.R.O.S. Eng., L.R.C.P. Lond, Clinical Pathologist, National Hospital for Paralysed

Upper Berkeley-street, $W$.

\section{REPORT OF THE ASYLUMS COMMITTEE OF THE LONDON COUNTY COUNCIL FOR THE YEAR ENDING MARCH 31st, 1911.}

\section{Statistios.}

THE average daily numbers on the registers of the nine London County Council asylums and epileptic colony was 19,997. There were admitted during the year 3727 patients, and 1143 persons were discharged recovered. There were 1645 deaths. The patients for whom on Jan. 1st, 1911, the Council was primarily responsible to find accommodation was 20,158 , this number including, besides the patients in the asylums, patients in other county and borough asylums under the committee's contracts or under arrangements made by the guardians. The accommodation available on Jan. Ist, 1910 (excluding Claybury Hall), was 19,867 beds, being an increase of 140 beds. The increase would have been greater but for a reduction in the accommodation for women effected at Hanwell Asylum through the disuse of some basement dormitories which had been adapted for occupation during a time of great pressure. The above number of patients is only a proportion of the total number coming under the purview of the London Poor-law authorities. It excludes patients in the Metropolitan Asylums Boards asylums, in workhouses, and those living with relatives and friends who are visited quarterly by the parish medical officer. This year's figures of the number of patients for whom the Council has been responsible show an increase of 244 on those for the previous year, and the rate of increase is again ascending, though the average rate of increase over the past 21 years appears to be declining.

Mental Ilospital: Selection of Site.

Plans of a new asylum on the villa principle to be erected on the Horton Estate are still in preparation. A contract for the purchase for $£ 10,000$ of two freehold properties at Denmark Hill has been entered into, and is waiting the approval of the Secretary of State. The land, some $4 \frac{1}{2}$ acres in area, it is hoped will provide a satisfactory site for the mental hospital for 100 patients towards the cost of which Dr. Henry Maudsley in 1908 promised to contribute a sum of $£ 30,000$. It appears that the task of selecting a suitable site within four miles of Charing Cross has been particularly difficult. So far as it is possible to form an estimate of the cost of building and equipment. it is anticipated that this will amount to another $£ 40,000$.

Recurrent Ins inity. ${ }^{1}$

Attention is drawn to a remarkable instance of a male patient admitted to Banstead Asylum on Feb. 13th, 1911, for the eighth time. This man is only 37 years old, and in addition to the periods passed at Banstead has been in Bethlem Royal Hospital, Ayrshire Asylum, the Kent County Asylum, Hanwell Asylum, and in a private licensed house. $\mathrm{He}$ has therefore been admitted to asylums on no less than 13 occasions. He married in 1903 and there are five children by the marriage, two males and three females (ages ranging from a little more than 1 year to 7 years), all of whom are now chargeable to the guardians of a London parish. The guardians' general relieving officer further states that the patient's wife is at present employed in service, but that the whole of the family have on and off been in receipt of indoor and outdoor relief since 1906.

These facts plainly indicate the great difficulty experienced in dealing with cases of recurrent insanity. Such cases, as the law stands at present, must be discharged as soon as they are apparently recovered, but it is often quite evident that with the removal of the fostering restraints of asylum life and the re-subjection of the patient to the stress and hardships of normal existence he will speedily break down. Moreover, as in the present instance, opportunity is afforded by the intervals of liberty for the propagation of children who must share in the mental and nervous instability of the parent, and who in their turn will probably swell the number of persons for whom asylum accommodation and care have to be provided.

Chapter XXIX. contains the report of the director of the Pathological Laboratory, Dr. F. W. Mott. It contains long lists of the papers issued and about to be issued. 